\title{
Osteoporotic vertebral fracture caused by topical corticosteroid abuse: A case report
}

\author{
STEFANO PIASERICO $^{1}$, DENNIS LINDER ${ }^{2}$, FRANCESCO MESSINA $^{1}$ and MAURO ALAIBAC ${ }^{1}$ \\ ${ }^{1}$ Dermatology Unit, Department of Medicine, University of Padua, \\ Padua I-35128, Italy; ${ }^{2}$ Department of Dermatology and Venereology, \\ Ben Gurion University of The Negev, Beer-Sheva 84101, Israel
}

Received January 10, 2019; Accepted July 17, 2019

DOI: $10.3892 /$ etm.2019.7825

\begin{abstract}
In the present case report, a 32-year-old man with a 20-year long history of psoriasis, who presented with severe lower back pain and had no records of previous trauma, is reported. The patient reported the regular use of clobetasol cream, for 8 years, at an average dosage of 100 grams (g) per week. At the time of visit, the patient presented with severe psoriasis, which was associated with a cushingoid appearance. An X-ray of the spine was performed and the results revealed diffuse vertebral collapse that was caused by osteoporosis. The patient was diagnosed with iatrogenic Cushing's syndrome caused by the long-term use of clobetasol 17-propionate cream. The topical clobetasol treatment was stopped and replaced with infliximab infusions. Complete control of the disease was subsequently achieved. Iatrogenic Cushing's syndrome is generally caused by systemic corticosteroid abuse. However, the topical application of potent glucocorticoids, including clobetasol treatment on the skin and mucosae, results in the same syndrome.
\end{abstract}

\section{Introduction}

Iatrogenic Cushing's syndrome is generally caused by systemic corticosteroid abuse; however, topical application of potent glucocorticoids such as clobetasol propionate on the skin and mucosae $(1,2)$, and intranasal use (3), may also result in Cushing's syndrome. Furthermore, while the stratum corneum typically serves as a barrier of drug absorption, thus reducing systemic availability, in diseases where there is an impairment of these barrier properties, enhanced percutaneous absorption of drugs may occur. Both systemically and topically applied steroids impair the permeability and homeostatic balance of the barrier and integrity of the stratum corneum (4). In particular, it has been demonstrated that even short-term use

Correspondence to: Professor Mauro Alaibac, Dermatology Unit, Department of Medicine, University of Padua, 4 Via Vincenzo Gallucci, Padua I-35128, Italy

E-mail:mauro.alaibac@unipd.it

Key words: vertebral fracture, topical corticosteroid, psoriasis of topically applied clobetasol propionate impairs epidermal structure and function (4). Therefore, corticosteroids may enhance its own absorption over time.

The suppression of the hypothalamic-pituitary-adrenal axis (HPA) and Cushing's syndrome as result of topical use of steroids have been reported in a number of cases, particularly in newborns or young children $(1,5,6)$ and pediatric patients who are more prone to develop the disease as a result of a higher ratio of body surface to weight and thus exhibit increased absorption of topically applied drugs. Cases of Cushing's syndrome in adult patients treated for extended periods with high doses of potent topical steroids appear to be less frequent $(7,8)$.

\section{Case report}

A 32-year-old man, a smoker since the age of 16 with a 20 -year long history of psoriasis, presented with severe lower back pain, which had begun 5 months earlier and was aggravated by flexion and extension of the lumbar spine. There were no records of previous trauma as a possible cause. The patient had been treated over the years with systemic cyclosporine ( $>1$ year) and acitretin ( $>8$ months) but primarily with topical drugs. The skin involvement of psoriasis had gradually increased with time, with lesions finally covering $90 \%$ of the body surface. The patient reported having regularly applied $0.5 \%$ clobetasol propionate cream for the previous 8 years at an average dosage of 100 grams $(\mathrm{g})$ per week. At the time of visit, he presented with moderate to severe psoriasis with a cushingoid appearance, numerous striae rubrae on the trunk of the body, generalized atrophy of the skin, truncal obesity, moon-like face and edema of the lower extremities. Blood pressure was $150 / 100 \mathrm{mmHg}$, laboratory evaluation of a blood sample revealed a leukocytosis a baseline morning cortisol level of 14 count of $12,400 / \mathrm{mm}^{3}$, neutrophilia count of $9,500 / \mathrm{mm}^{3}$, an increased platelet count of $460,000 / \mathrm{mm}^{3}$, a slightly reduced red blood cell count of $4.1 \mathrm{million} / \mathrm{mm}^{3}$ and a haemoglobin count of $10.9 \mathrm{~g} / \mathrm{dl}$. The ACTH level was $<5 \mathrm{ng} / \mathrm{l}$ and nmol/1 (normal range, 198-695 nmol/l). The patient's height was $150 \mathrm{~cm}$ with a reported total height loss of $20 \mathrm{~cm}$ over the course of the previous 5 years. An X-ray of the spine was subsequently performed and revealed diffuse vertebral collapse caused by osteoporosis (Fig. 1). Bone densitometry showed a femoral neck $\mathrm{T}$ score of -4.2 and a lumbar vertebra 


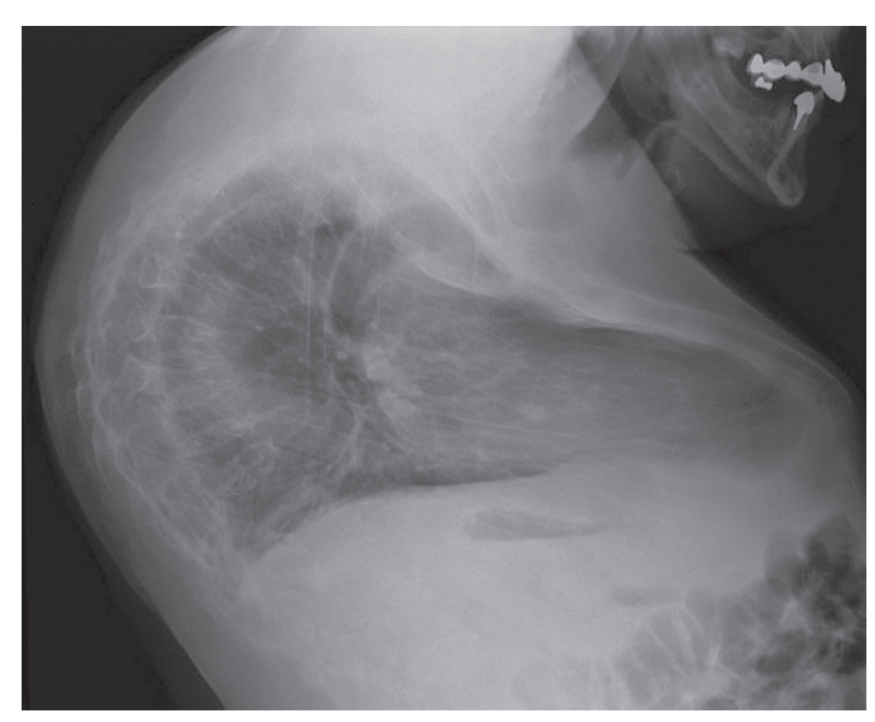

Figure 1. Patient X-ray. X-ray showed diffuse vertebral collapse, primarily involving the thoracic and lumbar segment, resulting in a height loss of $20 \mathrm{~cm}$ in the patient.

(L1-L4) $\mathrm{T}$ score of -6.3.The osteocalcin level was $2.8 \mu \mathrm{g} / \mathrm{l}$ (normal range, 7-22 $\mu \mathrm{g} / \mathrm{l}$ ), urine deoxypyridinoline level was $15 \mathrm{nmol} / \mathrm{l}$ creatinine (normal range 2.3-5.4 nmol/1), testosterone level was $4.91 \mathrm{nmol} / 1$ (normal range, 10-29 nmol/l) and dehydroepiandrosterone level was $0.1 \mu \mathrm{mol} / 1(3.5-10.5 \mu \mathrm{mol} / \mathrm{l})$.

The patient was diagnosed with iatrogenic Cushing's syndrome caused by long-term use of clobetasol 17-propionate cream. The topical treatment with clobetasol propionate was phased out and replaced with infliximab infusions $(5 \mathrm{mg} / \mathrm{kg})$ as at that time was the only biological available for the treatment of psoriasis, and complete control of the disease was achieved after 4 weeks.

In addition, $5 \mathrm{mg}$ of alendronate once daily was prescribed to limit further progression of osteoporotic damage. A total of 3 months after diagnosis of vertebral collapse, ACTH levels were at physiological levels ( $28 \mathrm{ng} / \mathrm{l})$ and there was no evidence of worsening bone damage.

\section{Discussion}

Iatrogenic Cushing's syndrome is generally caused by systemic corticosteroid abuse but may be caused by topical application of potent glucocorticoids such as clobetasol propionate on the skin and mucosae $(1,2)$, and by inhalation (3). Furthermore, whilst the stratum corneum usually acts as a barrier for drug absorption thus reducing systemic availability, in diseases where an impairment of these barrier properties is a side effect, an enhanced percutaneous absorption of drugs may occur. Both systemic and topical steroids impair the homeostasis of the permeability barrier and stratum corneum integrity (4). It has been demonstrated that even short-term treatment with topical clobetasol propionate impairs epidermal structure and function (4). Therefore, the topical administration of corticosteroids may enhance absorption of itself overtime.

Temporary iatrogenic Cushing's syndrome from topical steroids was first described in 1971 (9). However, only two cases of vertebral collapse due to osteoporosis caused by application of topical glucocorticoids have been reported in literature to date: Young et al (10) reported a 53-year-old man with cushingoid appearance and osteoporosis causing lumbar and thoracic vertebral collapse due to topical clobetasol propionate use for 5 years and ,more recently Gonül and Gonül (11) described a 42 year-old male heavy smoker who developed multiple costal and vertebral fractures after use of clobestal propionate, 2-3 times a week for 20 years.

The risk of iatrogenic Cushing's syndrome from topical steroids increases according to several factors, including the potency of the glucocorticoid used, the dose applied and surface area where the dose was applied to, skin thickness and location (with the eyelid and scrotum showing the highest degree of penetration and the side of the foot the least) the presence of fissurated skin, the age of the patient (with children demonstrating increased absorption), the use of occlusive dressings which promote absorption, the vehicle (ointments increase penetration) and the duration of use.

Osteoporosis represents one of the most threatening consequences of Cushing's syndrome. The impairment of the bone frame in osteoporosis enhances the fragility of the bone and increased risk of fractures. Drug-induced osteoporosis is one of the most common causes of secondary osteoporosis in younger patients. In particular, glucocorticoids, L-thyroxine, heparin and anticonvulsants may lead to development of osteoporosis in patients treated with long-term therapies for chronic diseases. The effect of glucocorticoids on the bones may arise through different mechanisms: i) Dysregulating $\mathrm{Ca}^{2+}$ homeostasis; ii) imbalance of steroid hormones; and iii) inhibition of bone formation and enhancement of bone resorption (12).

In case of a suspected Cushing's syndrome, measurement of a morning serum cortisol levels are useful. If the levels are $>5 \mu \mathrm{g} / \mathrm{dl}$, the patient may be exhibiting adrenal suppression. Confirmation of diagnosis and management of Cushing's syndrome should however be handled by an endocrinologist. In such a context, the use of tumor-necrosis factor- $\alpha$, interleukin (IL)-23 and/or IL-17 inhibitors may prove beneficial by improving bone metabolism (13-15).

The present case was of particular interest as the vertebral collapse occurred at a relatively young age (32 years) and the severity of the clinical and radiological diagnosis was unexpectedly dispropotionate to either the age of the patient and the modality of use. To this regard, magnetic resonance imaging scan may help to better characterize the microarchitectural bone alterations determined by the therapy, but in this case it was not performed. The case reported highlights the risk of the inappropriate continued use of potent corticosteroid creams, potentially leading to permanent and potentially dibilitating consequences. The additional risk factor for osteoporosis determined by smoking may have contributed to the vertebral collapse as previously described (7). Since patients with psoriasis are more likely to be smokers, the use of topical steroids over longer periods in these patients will require additional monitoring.

\section{Acknowledgements}

Not applicable.

\section{Funding}

No funding was received. 


\section{Availability of data and materials}

Data sharing is not applicable to this article, as no datasets were generated or analyzed during the current study.

\section{Authors' contributions}

SP and MA performed the acquisition, analysis and interpretation of data, drafted the manuscript and revised it critically for important intellectual content. DL and FM performed analysis and interpretation of data, drafted the manuscript and revised it critically for important intellectual content. All authors read and approved the manuscript and agree to be accountable for all aspects of the research in ensuring that the accuracy or integrity of any part of the work are appropriately investigated and resolved.

\section{Ethics approval and consent to participate}

Not applicable.

\section{Patient consent for publication}

Written informed consent was obtained.

\section{Competing interests}

The authors declare that they have no competing interests.

\section{References}

1. Tempark T, Phatarakijnirund V, Chatproedprai $\mathrm{S}$ Watcharasindhu S, Supornsilchai V and Wananukul S: Exogenous Cushing's syndrome due to topical corticosteroid application: Case report and review of the literature. Endocrine 38: 328-334, 2010.

2. Decani S, Federighi V, Baruzzi E, Sardella A and Lodi G: Iatrogenic Cushing's syndrome and topical steroid therapy: Case series and review of the literature. J Dermatolog Treat 25 : 495-500, 2014
3. Dutta D, Shivaprasad KS, Ghosh S, Mukhopadhyay S and Chowdhury S: Iatrogenic Cushing's syndrome following short-term intranasal steroid use. J Clin Res Pediatr Endocrinol 4: $157-159,2012$.

4. Kao JS, Fluhr JW, Man MQ, Fowler AJ, Hachem JP, Crumrine D, Ahn SK, Brown BE, Elias PM and Feingold KR: Short-term glucocorticoid treatment compromises both permeability barrier homeostasis and stratum corneum integrity: Inhibition of epidermal lipid synthesis accounts for functional abnormalities. J Invest Dermatol 120: 456-464, 2003.

5. Ermis B, Ors R, Tastekin A and Ozkan B: Cushing's syndrome secondary to topical corticosteroids abuse. Clin Endocrinol (Oxf) 58: 795-796, 2003.

6. Gilbertson EO, Spellman MC, Piacquadio DJ and Mulford MI: Super potent topical corticosteroids use associated with adrenal suppression: Clinical consideration. J Am Acad Dermatol 38: 318-321, 1998.

7. Ohman EM, Rogers S, Meenan FO and McKenna TJ: Adrenal suppression following low-dose opical clobetasol propionate. J R Soc Med 80: 422-424, 1987.

8. Ohnishi T, Suzuki T, Watanabe $\mathrm{S}$ and Takahashi $\mathrm{H}$ : Erythrodermic psoriasis associated with hyperuricemia and iatrogenic Cushing's syndrome due to topical corticosteroid therapy. Int J Dermatol 35: 379-380, 1996.

9. Keipert JA and Kelly R: Temporary Cushing's syndrome from percutaneous absorption of betamethasone 17-valerate. Med J Aust 1: 542-544, 1971.

10. Young CA, Williams IR and MacFarlane IA: Unrecognised Cushing's syndrome and adrenal suppression due to topical clobetasol propionate. Br J Clin Pract 45: 61-62, 1991.

11. Gönül $\mathrm{M}$ and Gönül E: A case of multiple bone fractures due to the use of topical corticosteroid therapy for psoriasis. J Dermatolog Treat 26: 215-216, 2015.

12. Compston J: Glucocorticoid-induced osteoporosis: An update. Endocrine 61: 7-16, 2018.

13. Haroon NN, Sriganthan J, Al Ghanim N, Inman RD and Cheung AM: Effect of TNF-alpha inhibitor treatment on bone mineral density in patients with ankylosing spondylitis: A systematic review and meta-analysis. Semin Arthritis Rheum 44: 155-161, 2014.

14. Molnár I, Bohaty I and Somogyiné-Vári É: IL-17A-mediated sRANK ligand elevation involved in postmenopausal osteoporosis. Osteoporos Int 25: 783-786, 2014

15. Shukla P, Mansoori MN and Singh D: Efficacy of anti-IL-23 monotherapy versus combination therapy with anti-IL-17 in estrogen deficiency induced bone loss conditions. Bone 110: 84-95, 2018. 